\title{
Comment on 'Effects of geography, taxa, water flow, and temperature variation on coral bleaching intensity in Mauritius' (McClanahan et al. 2005)
}

\author{
R. van Woesik ${ }^{1, *}$, T. Nakamura ${ }^{2}$, H. Yamasaki ${ }^{2}$, C. Sheppard ${ }^{3}$ \\ ${ }^{1}$ Department of Biological Sciences, Florida Institute of Technology, 150 West University Boulevard, Melbourne, \\ Florida 32901-6975, USA \\ ${ }^{2}$ Faculty of Science, University of the Ryukyus, Nishihara, Okinawa 903-0213, Japan \\ ${ }^{3}$ Department of Biological Sciences, University of Warwick, Gibbet Hill Road, Coventry CV4 7AL, UK
}

Water flow and coral bleaching. McClanahan et al. (2005) attempted to identify causative agents responsible for coral bleaching at 15 sites around Mauritius over a 21 d period in March 2004. However, a causeeffect relationship is often difficult to detect in the field. We previously showed that flow-treated colonies had higher survival under stressful temperature and irradiance (Nakamura \& van Woesik 2001), and that recovery from bleaching was facilitated by water flow rate (Nakamura et al. 2003). In contrast, McClanahan et al. (2005) argued that higher water flow rates during periods of high water temperatures resulted in more intensive coral bleaching.

McClanahan et al. (2005) criticized our prior studies on the positive effects of water flow and coral survival under temperature and irradiance stress (Nakamura \& van Woesik 2001). They argued that our corals were not acclimated for a sufficient period (2 wk in Nakamura \& van Woesik 2001; 3 mo in Nakamura et al. 2003). They suggested that, had we acclimated the colonies for a longer period, our results could have been different. But it is inappropriate for us to speculate on results we do not have. Moreover, Lesser et al. (1994) showed significant increases in the activities of all antioxidant enzymes and net and gross photosynthesis (normalized to surface area) with increasing water velocity after high-flow coral morphologies were left to acclimatize for $13 \mathrm{~d}$ to different flow regimes; further, Anthony \& Hoegh-Guldberg (2003) showed that photoacclimation of coral symbiosis occurs within 1 to $2 \mathrm{wk}$.

Mass-transfer principles are at the very foundation of our work. Van Woesik and colleagues showed theoret- ically that small coral colonies should survive thermal and irradiance stress more readily than large coral colonies. This has been confirmed in the field, as juvenile coral colonies are more resistant to a combination of high temperature and high irradiance compared with large corals (Loya et al. 2001, Bena \& van Woesik 2004). Most recently, our work has shown that coral bleaching is less likely to occur in environments affected by water flow, because photoinhibition is reduced (Nakamura et al. 2005). We measured water flow rates with an electro-magnetic flow sensor (ACM 200, ALEC Electronics) in experimental flumes and subjected our samples to a variety of water flow rates. McClanahan et al. (2005) used 'ice-cube tray' sized clod cards, deployed for $24 \mathrm{~h}$ (n was not specified), as proxies of water flow rate. Clod cards are useful proxies to derive estimates of water flow rates, but they need to be treated with caution (Porter et al. 2000). Calcium sulphate clod cards dissolve in accordance with water flow rates (as specified by McClanahan et al. 2005), but dissolution is also temperature dependent (Anzai 2001). The other problem with clod card measurements is scale: while habitat-wide differences may be grossly estimated, although they are temperature-dependent, small differences in flow are less likely to be detected using clod cards. Therefore, the precision of the clod cards characterizing water flow rates in the direct vicinity of the coral colonies is questionable in the study by McClanahan et al. (2005).

A correlation between high water flow rates and coral bleaching (McClanahan et al. 2005) does not demonstrate that severe bleaching is caused by high flow rates. High-flow sites commonly support a high 
abundance of Acropora colonies, which also happen to be temperature sensitive (Loya et al. 2001). The authors dismiss the possibility that spatial differences in coral community composition lead to spatial differences in bleaching response, based on the results of their covariance-based principal component analysis (PCA) on the 26 dominant coral taxa and 15 sites. They 'correlated the first and second component or $x$ and $y$ Eigenvalues against the $\mathrm{BI}^{\prime}$ [bleaching index] (McClanahan et al. 2005, p. 134). Correlating dominant PCA eigenvalues against the BI was not possible because the matrix dimensions do not agree; what they actually correlated were the Principal Component scores associated with the 2 largest eigenvalues, not the actual eigenvalues, against the bleaching index. Lack of correlation, however, does not imply community uniformity, irrespective of the variance expressed by the eigenvalues, because their PCA, like most ecological PCAs using site-species matrices, will be dominated by just a few common species. Indeed, McClanahan et al. (2005, p. 141) note 'In Mauritian lagoons, the dominance of hard coral cover, notably created by large stands of Acropora and other taxa, appears to be most common on the eastern side of the island', where most bleaching was recorded.

Spatial variability in coral bleaching. McClanahan et al. (2005) continue their argument that, since the communities did not vary spatially (despite the comment quoted above), and since they recorded a spatially variable bleaching effect, then either (1) conditions to which the corals were accustomed differed, (2) local environmental conditions differed during or just prior to bleaching, or (3) both the background conditions and conditions during the bleaching event differed locally. McClanahan et al. (2005) argued that differential variance in background conditions was the principal reason for differential bleaching responses. Yet they showed no evidence for this, nor did they show whether areas with higher local currents received the water from the warm, extensive Mauritius lagoon, or from cooler offshore areas. In fact the regression of temperature variation (as a standard deviation) against the bleaching index showed no significant relationship (in addition, the tests are invalid because one cannot undertake a significance test after the variables have already been selected; cf. McClanahan et al. 2005, Table 2b). It is indeed plausible that an environment with consistently high water flow may have a lower variance in water temperature, and corals in stenothermic habitats may be more sensitive to regional temperature anomalies, but there was no evidence for this in McClanahan et al. (2005). The vast differences in scale of the variables they measured, where a proxy for flow was measured at $10^{-2} \mathrm{~m}(10 \mathrm{~cm})$ and temperature at a scale of $10^{3} \mathrm{~m}(9 \mathrm{~km}$ satellite res- olution), may in part explain this lack of evidence. Indeed, McClanahan et al. (2005, p. 140) 'suspect that the actual temperature variation between sites was different and if the temperature data were more closely associated with the study sites than (sic) the relationship between the BI, water flow and temperature variation would be stronger.' But, carefully conducted physiological experiments would be required to demonstrate cause and effect.

McClanahan et al. (2005, p. 131) say that Sheppard (2003) predicted 'that corals in the western Indian Ocean's southern hemisphere will become ecologically extinct within the next 20 to $40 \mathrm{yr}^{\prime}$, but we think that this is an oversimplification of Sheppard's statements. Sheppard stated that sites of low latitudes are predicted to do so, with a more distant time frame north and south of a band between approximately the equator and $15^{\circ} \mathrm{S}$. The model does not predict bleaching per $s e$, but predicts when there will be a particular probability of the 1998 peak temperatures recurring. McClanahan et al. (2005) conducted their study at a site in the Indian Ocean where sea surface temperature (SST) in 1998 was markedly depressed by heavy cloud cover. Mauritius cannot be regarded as representative in this respect. Sites such as the Seychelles granitic islands ( 4 to $5^{\circ} \mathrm{S}$ ), the Chagos Archipelago (4 to $7^{\circ} \mathrm{S}$ ) and the Maldives north of the equator have already been affected by repeated bleaching and mortality episodes, in accordance with, or even worse than, Sheppard's (2003) predictions. Likewise, in the Caribbean (Sheppard \& Rioja-Nieto 2005) the model predicts that southeastern and eastern reef areas will become affected before northwestern areas, and the SST patterns seen in late 2005 are notable in this respect.

Why is Mauritius so different? McClanahan et al. (2005) assume a 'local bleaching threshold' of $\sim 27.5^{\circ} \mathrm{C}$. The HadISST1 data give higher SST values at Mauritius for 4 mo continuously $\left(>28^{\circ} \mathrm{C}\right.$ for $\left.3 \mathrm{mo}\right)$, peaking at $28.75^{\circ} \mathrm{C}$ in February 1998 , but this did not lead to significant bleaching or mortality. It is probable that SST was suppressed by $\geq 1^{\circ} \mathrm{C}$ due to strong cyclonic conditions, given that SST was $>29^{\circ} \mathrm{C}$ in much of the area. But data sets should not be 'mixed'. The prediction made by Sheppard (2003) was that the 1998 peak temperature (using HadISST1 data) would be reached in a certain time period (by about 2025 for Mauritius). We think that in the absence of unusual cloud cover, the temperature at Mauritius would have been nearer to $29.5^{\circ} \mathrm{C}$ in 1998 . The 0.2 probability of recurrence in that case (and Sheppard's predicted date of reef extinction there) is delayed to about 2060. Mauritius was an unfortunate choice of site for McClanahan et al.'s (2005) study, but the lack of high mortality makes it a good area for conservation management. 


\section{LITERATURE CITED}

Anthony KRN, Hoegh-Guldberg O (2003) Kinetics of photoacclimation in corals. Oecologia 134:23-31

Anzai R (2001) The effects of coral morphology and waterflow rates on rates of coral growth and passive diffusion. MSc thesis, University of the Ryukyus, Okinawa

Bena C, van Woesik R (2004) The impact of two bleaching events on the survival of small coral colonies (Okinawa, Japan). Bull Mar Sci 75:115-125

Lesser MP, Weis VW, Patterson MR, Jokiel PL (1994) Effects of morphology and water motion on carbon delivery and productivity in the reef coral, Pocillopora damicornis (Linnaeus): diffusion barriers, inorganic carbon limitation, and biochemical plasticity. J Exp Mar Biol Ecol 178: 153-179

Loya Y, Sakai K, Yamazato K, Nakano Y, Sambali H, van Woesik R (2001) Coral bleaching: the winners and the losers. Ecol Lett 4:122-131

McClanahan TM, Maina J, Moothien-Pillay R, Baker AC (2005) Effects of geography, taxa, water flow, and temper-

Editorial responsibility: Charles Birkeland (Contributing Editor), Honolulu, Hawaii, USA ature variation on coral bleaching intensity in Mauritius Mar Ecol Prog Ser 298:131-142

Nakamura T, van Woesik R (2001) Water-flow rates and passive diffusion partially explain differential survival of corals during the 1998 bleaching event. Mar Ecol Prog Ser 212:301-304

Nakamura T, Yamasaki H, van Woesik R (2003) Water flow facilitates recovery from bleaching in the coral Stylophora pistillata. Mar Ecol Prog Ser 256:287-291

Nakamura T, van Woesik R, Yamasaki H (2005) Photoinhibition of photosynthesis is reduced by water flow in the reefbuilding coral Acropora digitifera. Mar Ecol Prog Ser 301: $109-118$

Porter ET, Sanford LP, Suttles SE (2000) Gypsum dissolution is not a universal integrator of 'water motion'. Limnol Oceanogr 45:145-158

Sheppard CRC (2003) Predicted recurrences of mass coral mortality in the Indian Ocean. Nature 425:294-297

Sheppard CRC, Rioja-Nieto R (2005) Sea surface temperature 1871-2099 in 38 cells in the Caribbean region. Mar Environ Res 60:389-396

Submitted: September 15, 2005; Accepted: November 1, 2005 Proofs received from author(s): November 11, 2005 